\title{
PI 525088-PMR, A Melon Race 1 Powdery Mildew-resistant Watermelon Line
}

\author{
Angela R. Davis ${ }^{1}$ \\ U.S. Department of Agriculture, Agricultural Research Service, South \\ Central Agricultural Research Laboratory, P.O. Box 159, Lane, OK 74555
}

\section{Amnon Levi}

U.S. Department of Agriculture, Agricultural Research Service, U.S. Vegetable Laboratory, Charleston, SC 29414

\section{Todd Wehner}

Department of Horticultural Science, Box 7609, North Carolina State University, Raleigh, NC 27695-7609

\section{Michel Pitrat}

INRA-Génétique et Amélioration des Fruits et Légumes, Montfavet, France

Additional index words. watermelon, Citrullus lanatus, powdery mildew, Sphaerotheca fuliginea, resistance, Podosphaera xanthii

PI 525088-PMR is a watermelon (Citrullus lanatus var. lanatus) line having resistance to melon race one powdery mildew (PM) Podosphaera xanthii (syn. Sphaerotheca fuliginea auct. p.p.). The line is derived from the U.S. Plant Introduction (PI) 525088 (Citrullus lanatus var. lanatus). PI 525088PMR does not have desirable fruit quality with fruit flesh color being white to light pink could be a useful parent for introducing race one powdery mildew ( $P$. xanthii) resistance into adapted watermelon cultivars.

\section{Origin}

PI 525088 was collected from Sawhaj, Egypt, and was placed in the USDA Griffins, and an average Brix value of 6 . However, it

Ga., Citrullus germplasm collection in 1986 . The working collection of Citrullus germplasm is kept at Griffin, Ga., and supplied seeds for this research. Experiments in 2000 suggested this line had resistance to race one PM. Originally, PI 525088 showed heterogeneity for race one powdery mildew resistance. Therefore, controlled self-pollinations of this line were made to produce a line homogeneous for race one PM resistance. Selection and self-pollination of the plant with the highest resistance to powdery mildew infection was repeated for five successive generations to produce PI 525088PMR seed. This line is monoecious, with small (3 kg), round fruit, a medium green skin with dark green stripes, and white to pink fruit color.

Received for publication 4 May 2006. Accepted for publication 5 July 2006.

Mention of trade names or commercial products in this article is solely for the purpose of providing specific information and does not imply recommendation or endorsement by the U.S. Department of Agriculture. All programs and services of the U.S. Department of Agriculture are offered on a nondiscriminatory basis without regard to race, color, national origin, religion, sex, age, marital status, or handicap. The article cited was prepared by a USDA employee as part of his or her official duties. Copyright protection under U.S. copyright law is not available for such works. Accordingly, there is no copyright to transfer. The fact that the private publication in which the article appears is itself copyrighted does not affect the material of the U.S. Government, which can be freely reproduced by the public. We thank Amy Helms and Anthony Dillard for technical assistance. Some of the melon differentials were supplied by Claude Thomas.

${ }^{1}$ To whom reprint requests should be addressed; e-mail adavis-usda@lane-ag.org. 2001a, 2001b). Seven pathogenically distinct races of $P$. xanthii have been reported based using differential reactions against 10 melon (Cucumis melo) genotypes (McCreight et al., 1987; Pitrat et al., 1998), and recently 28 races have been described on a larger set of 32 melon genotypes (McCreight, 2006). Cur- rently, two races ( 1 and 2 ) have been reported on watermelon (Davis et al., 2002; McGrath, 2001b).

Efforts leading to the development of PI 525088-PMR were initiated in 2000. A total of 100 PI accessions were evaluated for naturally occurring race one PM in field studies in Lane, Okla. Of these, PI 525,088 was the most resistant to PM in growth chamber and field studies (Davis et al., 2001, 2002). In 2004 and 2005, PI 525088PMR plants, along with other Citrullus sp., including evaluations of the U.S. Plant Introduction (PI) collection of Citrullus (including Citrullus lanatus var. lanatus, $C$. lanatus var. citroides, C. colocynthis, and Praecitrullus fistulosus), were evaluated for resistance to race one powdery mildew $P$. xanthii in greenhouse studies. Cultigens were evaluated for resistance to naturally occurring race one powdery mildew at Lane, Okla. In this evaluation, PI 525088-PMR plants appeared to be among the most resistant of 1560 Citrullus PI lines, never showing higher than $12 \%$ coverage of leaf surface with disease symptoms. Susceptible control plants had ratings as high as $80 \%$ coverage and consistently had disease symptoms over $35 \%$ of their leaf surfaces. The inheritance of race one PM resistance in an F2 population of PI $525088 \times$ x Black Diamond was found to be multigenic (Davis et al., 2002).

Figure 1 demonstrates the severity of race one PM on susceptible plants grown under greenhouse culture. The figure shows plants grown side by side in a greenhouse. Both plants are the same age and the picture was taken on the same day. The plant on the left is Dixielee x Black Diamond F1 (susceptible), and the plant on the right is PI 525088-PMR (resistant). Leaves from the same plants shown in Fig. 1 are depicted in Fig. 2 and demonstrate the desiccated look of a highly infected leaf on a susceptible plant (left) versus a healthy leaf from a resistant plant, PI 525088-PMR (right).

PI 525088 was demonstrated to have some tolerance to race two powdery mildew in a growth chamber experiment in Charleston, S.C., in 2001 and in a greenhouse test in Raleigh, N.C., in 2005. Experiments in 2004 showed that PI 525088-PMR was fully resistant to muskmelon race one, France two, three, and five of powdery mildews tested using a leaf disk assay in Montfavet, France (disease rating of 0 on a $0-9$ scale of increasing severity to all races). PI 525088 showed intermediate to susceptible reactivity to gummy stem blight (Didymella bryoniae (Auersw.) Rehm) (Gusmini et al., 2005) and susceptibility to fruit blotch (Acidovorax avenae subsp. citrulli) by experiments performed at the University of Florida by Don Hopkins (USDA GRIN Database; www. ars-grin.gov).
Availability

Small amounts of seed of PI 525088-PMR are available for distribution to interested research personnel and plant breeders who make 

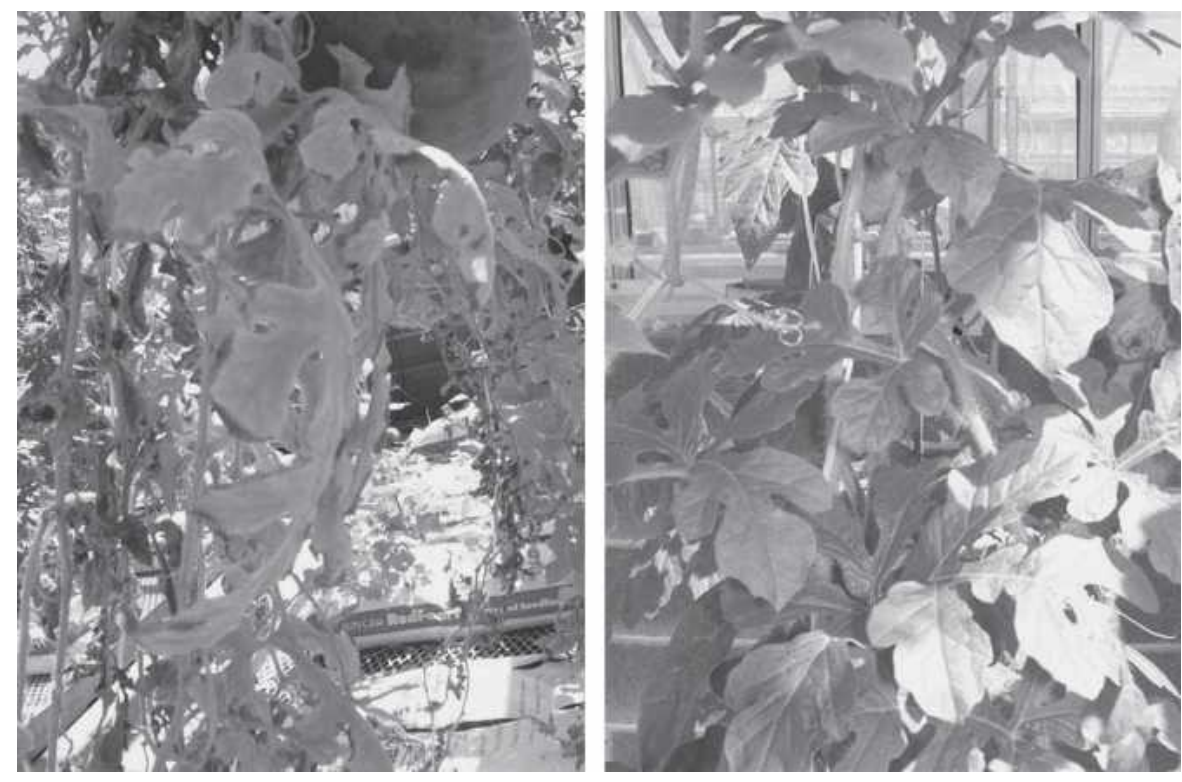

Fig. 1. Whole plant response to infection with powdery mildew in greenhouse-grown watermelon plants is shown. The plant on the left is Dixielee x Black Diamond F1 (susceptible), and the plant on the right is PI 525088-PMR (resistant).

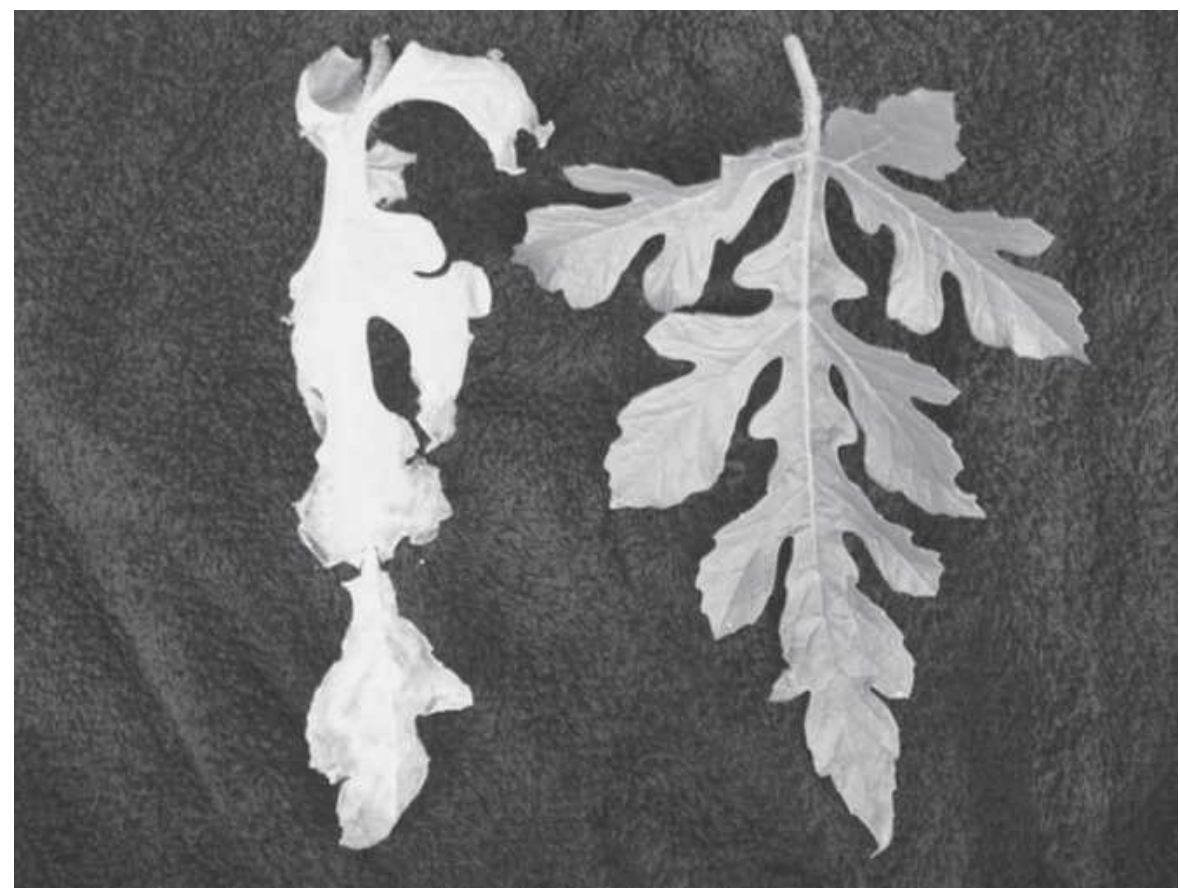

Fig. 2. Leaves from the same plants in Figure 1 are shown. The susceptible plant leaf is on the left and the PI 525088-PMR leaf is on the right. written request to Dr. Angela R. Davis, South Central Agricultural Research Laboratory, P.O. Box 159, Lane, OK 74,555 (e-mail: adavisusda@lane-ag.org). Seeds of PI 525088-PMR will also be submitted to the National Plant Germplasm System where they will be available for research purposes, including the development and commercialization of new cultivars. It is requested that appropriate recognition of the source be given when this germplasm contributes to research or development of a new breeding line or cultivar.

\section{Literature Cited}

Bertrand, F. 1991. Les Oidiums des Cucurbitacees: Naintien en culture pure, etude de leur variabilite et de la sensibilite chez le melon. Ph.D Diss. Univ. of Paris XI, Orsay, France.

Davis, A.R., B.D. Bruton, S.D. Pair, and C.E Thomas. 2001. Powdery mildew: An emerging disease of watermelon in the United States. Cucurbit Genet. Coop. Rpt. 24:42-48.

Davis, A.R., C.E. Thomas, A. Levi, B.D. Bruton, and S.D. Pair. 2002. Watermelon resistance to powdery mildew race 1, p. 192-198. In: D.N Maynard (ed.). Cucurbitaceae '02. ASHS Press, Alexandria, Va.

Epinat, C., M. Pitrat, and F. Bertrand. 1993. Genetic analysis of resistance of five melon lines to powdery mildews. Euphytica 65 $135-144$.

Gusmini, G., R. Song, and T.C. Wehner. 2005 New sources of resistance to gummy stem blight in watermelon. Crop Sci. 45:582-588.

McCreight, J.D. 2006. Melon-powdery mildew interactions reveal variation in melon cultigens and Podosphaera xanthii races 1 and 2. J. Amer. Soc. Hort. Sci. 131:59-65.

McCreight, J.D., M. Pitrat, C.E. Thomas, A.N Kishaba, and G.W. Bohn. 1987. Powdery mildew resistance genes in muskmelon. J. Amer. Soc. Hort. Sci. 112:156-160.

McGrath, M. 2001a. Fungicide resistance in cucurbit powdery mildew: Experiences and challenges. Plant Dis. 85:236-245.

McGrath, M.T. 2001b. Distribution of cucurbit powdery mildew races 1 and 2 on watermelon and muskmelon. Phytopathol. 91:S197 (Abstract).

McGrath, M.T. and C.E. Thomas. 1996. Powdery mildew, p. 28-30. In: T.A. Zitter, D.L. Hopkins, and C.E. Thomas (eds.). Compendium of Cucurbit Diseases. The Amer. Phytopathol. Soc., St. Paul, Minn.

Pitrat, M., C. Dogimont, and M. Bardin. 1998 Resistance to fungal diseases of foliage in melon, p. 167-173. In: J.D. McCreight (ed.). Cucurbitaceae'98. ASHS Press, Alexandria, Va. 